\title{
MY FAIR TRADE: A INTRODUÇÃO E ALGUMAS DAS NOTAS DE UMA NOVA TRADUÇÃO DO PIGMALIÃO, DE G. B. SHAW
}

\author{
Inacio Abdulkader, Angélica E. Gomes Caruy, \\ Fábio Garcia Neira, Hamilton Moura Ribeiro, \\ Lúcia Helena Zanetti, Stella E. O. Tagnin*
}

\begin{abstract}
RESUMO: O artigo apresenta a introdução e as notas para uma nova tradução do Pigmalião, de George Bernard Shaw. Além da usual apresentação e discussão de dificuldades e soluções de tradução, o texto busca apresentar um breve histórico da peça e algumas considerações acerca de sua inserção na vida e na obra de Shaw. Ademais, a aplicação prática, no trabalho em pauta, de alguns conceitos de teóricos da tradução teatral, como em Bassnett (1985) e Betti (2003), é apontada e explicitada. Buscamos também fazer ver que a condição específica de Pigmalião - o tratar-se de uma peça em que a própria língua tem o destaque de um personagem principal, com falas que precisam ser freqüentemente "desenhadas" - permite que se reconheçam nessa peça teatral situações tradutórias que ficam "entre o verbal e o visual", como o apontado, em outra situação tradutória, por Oittinen (1995). Pigmalião faz também ressaltar a "estratégia cooperativa” de Bassnett (1985) como, de longe, a mais conveniente para a tradução teatral
\end{abstract}

UNITERMOS: tradução de textos de teatro; lingua e condição social; cockney; George Bernard Shaw

\footnotetext{
* Os autores são ex-alunos do Curso de Especialização em Tradução CETRAD - Inglês do Departamento de Letras Modernas da FFLCH-USP, à exceção da última autora, que é a professora doutora que lhes ministrou, no segundo semestre de 2003, a disciplina "Tradução Literária" da grade do CETRAD. Uma primeira versão do que vai apresentado neste artigo fez parte do trabalho submetido pelos cinco primeiros autores como trabalho para a avaliação final da mencionada disciplina. O primeiro autor é atualmente mestrando no DLM / FFLCH - USP (kader@allnet.com.br).
} 
ABSTRACT: This article presents the introduction, translation notes and general notes of a new Portuguese translation of George Bernard Shaw's Pygmalion. Besides the usual presentation and discussion of translation problems and their solutions, historical data on the play and its role in Shaw's life and within his work is briefly considered. We further point to the practical application in this translation work of some concepts developed by theorists of the translation of theatre texts, such as Bassnett (1985) and Betti (2003). We also point out that Pygmalion's unique condition - a play where language figures with the prominence of a main character, with lines that frequently require for their construction an effort akin to the drawing of an illustration - allows one to recognize in the translation work situations "between the verbal and the visual" as noted, in a different translation condition, by Oittinen (1995). Also, Pygmalion highlights the "cooperative strategy" of Bassnett (1985) as, by far, the most convenient strategy for the translation of theatre texts.

KEYWORDS: translation of theatre texts; language and social condition; cockney; George Bernard Shaw

\section{My Fair Trade: uma introdução à tradução de Pigmalião}

\subsection{Shaw e o Pigmalião}

A oportunidade de se traduzir uma peça de teatro na qual a língua é personagem de destaque, usada como índice (e estigma) de condição social, é sem dúvida fascinante e desafiadora.

E, se a peça é Pigmalião, o grande sucesso de Bernard Shaw no qual se baseou o musical My Fair Lady, que, filmado, é hoje um cult, nossa opção por enfrentá-la se explica. E se é também justificada, deixamos ao julgamento do leitor - e em especial ao do tradutor de oficio - que se disponha a pacientemente acompanhar-nos até o final.

"Um dos mais devastadores fracassos iniciais na história da literatura" (Henderson, 1954: 469B), George Bernard Shaw, 
ao publicar, aos 83 anos, sua última peça - Nos tempos dourados do bom rei Charles - foi saudado como "our sole angel".

Entre esses dois momentos, o caixa de uma administradora de bens irlandesa que aos 20 anos trocara Dublin por Londres passou de "desempregado incorrigivel" (Henderson, 1954: 469B) a ghost writer malsucedido e autor literário que só encontrava abrigo em publicações de propaganda política radical. Isso lhe valeu uma conversão ao socialismo, um envolvimento com idéias marxistas e uma posição de liderança na recém-fundada Fabian Society, de cunho socialista não-marxista. Ao editar, em 1887, os Fabian Essays, tornou-se o responsável por um dos eventos mais marcantes no socialismo de seu tempo, que redundaria na fundação do Partido Trabalhista, em 1906 (Cole, 1954: 20).

Seu período de produção teatral (1885-1939) foi maior que o período de vida de Shakespeare, a quem Shaw censurava por ter escrito peças que "não continham mensagem para a sua época". E, como primeiro economista na história a se tornar autor teatral de sucesso mundial, registrou: "Em todas as minhas peças, meus estudos de economia desempenham um papel tão importante quanto o conhecimento da anatomia desempenhou nas obras de Michelangelo." (Henderson, 1954: 470).

De fato, as peças de Shaw são mais do que dramas no sentido clássico. Nelas se retratam o confronto de idéias e o conflito das ideologias de seu tempo. Shaw não se interessa pelos eventos da trama em si, mas pela reação das pessoas a eles. Seus prefácios cuidadosos - e, no caso específico de Pigmalião, também a "Seqüência", escrita num magnifico estilo jornalístico - somam-se a rubricas de uma qualidade literária que transcendem a mera instrução cênica e compõem um todo de obra que justifica, por exemplo, em Pigmalião, o subtítulo: um romance em cinco atos (grifo nosso). (Vide, a esse respeito, a nota de tradução 1, NT 1, na seção 2, "Notas de Tradução", abaixo. Nessa seção 2, apresentamos as NTs que julgamos relevante fazer constar deste artigo. Vide também as NT 7 e NT 9, acerca da qualidade literária das rubricas de Shaw).

Pigmalião, a mais notória das poucas peças para as quais Shaw autorizou a adaptação para o cinema, teve sua première 
em outubro de 1913, em Viena. Esse local de estréia pode parecer surpreendente, mas é preciso lembrar que já em 1904 Shaw era aclamado como o "rei da cena alemã" e que, em 1905, conquistava com Homem e super-homem o público de teatro nos Estados Unidos (Henderson, 1954: 470).

Estreando em Londres em abril de 1914, a peça fez sucesso de imediato. Foi publicada em 1916 (Constable \& Company, Londres) e teve em 1942 adicionadas algumas cenas. A primeira publicação, que inclui a totalidade dessas cenas, as quais requerem uma infra-estrutura cênica "mais elaborada, e possível apenas na tela de cinema ou em palcos que disponham de maquinaria excepcionalmente sofisticada", é a de 1942 (Penguin Books, Toronto, com ilustrações de Feliks Topolski), e foi a que adotamos para a tradução. De fato, pode-se reconhecer nessas cenas adicionais a base para muito do que de mais marcante há em My Fair Lady.

Nesse sentido, cabe deixar registrado que a "Unabridged Dover (1994) Republication of the work originally published [...] [in] 1916", sem estar a rigor afirmando nenhuma inverdade, vende a impressão de ser a obra completa, o que definitivamente não é.

Num dos trechos mais citados do Prefácio, Shaw se compraz em contradizer "os que papagueiam que a arte nunca deve ser didática", já que Pigmalião, que é "intensa e deliberadamente didática" e aborda "um assunto [a fonética] considerado tão árido", conseguiu não obstante ser um permanente sucesso em âmbito mundial. "Isso serve para provar meu argumento de que a grande arte não pode ser outra coisa [senão didática]". Eis aqui, como mencionado acima, a mensagem já no Prefácio.

Note-se, aliás, que a fonética para Shaw foi mais do que um pretexto de enredo para uma peça. É dele a concepção do "Shavian Alphabet" ("Shavian" = "de Shaw"), "o mais radical" - é claro - "programa de reforma do alfabeto", dentre os vários propostos ao longo dos séculos XIX e XX. O alfabeto foi desenvolvido de fato apenas em 1958, após a morte de Shaw, por Kingsley Read, vencedor do prêmio de quinhentas libras que Shaw estipulara para a melhor realização efetiva de um alfabeto Shavian (Rasula \& McCaffery, 1998; Read, 1998). 
Trata-se de um extenso alfabeto com mais de quarenta caracteres, que visa a cobrir com maior precisão as nuances fonéticas da lingua. Difere radicalmente do alfabeto romano lembrando "os alfabetos dravidianos do sul da Índia". Conforme determinação expressa de Shaw, uma edição de sua peça Ândrocles e o Leão foi então publicada com textos paralelos nos alfabetos romano e Shavian (Rasula \& McCaffery, 1998). Ainda quanto à fonética em Pigmalião, veja-se a NT 2.

Pigmalião, porém, aborda mais do que a fonética em si. É mais do que uma adaptação do mito grego (narrado nas Metamorfoses de Ovídio, 16 d.C.) acerca do escultor Pigmalião, que se apaixona pela estátua de Afrodite que esculpiu e que consegue, por concessão da deusa, tê-la transformada na jovem que desposará. Seu tema é a (i)mobilidade social, as vicissitudes ou as reações - de quem, em movimento ascendente, tem na própria fala um estigma. E até mesmo as de quem, em movimento descendente, vive a angústia permanente de à dura pobreza dar ar de nobreza.

E o fato de que a comédia (ou o drama) é um verniz que recobre a mensagem - o fundo, quase que de morality play - fica claro em várias passagens. Como, por exemplo, na cena do Ato II em que Doolittle, o pai de Eliza, tenta extorquir de Higgins cinco libras para que a filha passe a morar em sua casa (de Higgins). Informado de que as intenções de Higgins são as melhores, ele retruca que não tem dúvidas a esse respeito: "Claro que são. Se não fossem, pedia logo cinqüenta." "Você não tem moral?!" "Não posso me dar a esse luxo. E nem o senhor teria se fosse pobre como eu..." O que deixa Higgins no dilema de que "sob o ponto de vista da moral é um crime dar-lhe um tostão que seja" e, ao mesmo tempo, sentir "que há - grosso modo-algo de justiça no que ele está pedindo".

O fascinante é ver Shaw comprimir em sete falas curtas a lição de que o comportamento ético não é passivel de normatização, não pode ser registrado num manual que se consulte, serenamente, caso a caso. E de que a ética, na vida real é construída na prática, em cada prosaico evento do dia-a-dia. Higgins acabará por oferecer dez libras a Doolittle, que aceitará apenas as cinco que pedira. 


\subsection{Problemas para o tradutor de Pigmalião}

Mas deixemos a filósofos da ética e críticos literários o que lhes cabe. Pigmalião traz para o tradutor dilemas suficientes com que se ocupar, já no mais básico da estratégia tradutória.

Manter a locação do original, ou transportá-la para o país da lingua de chegada? Como traduzir o cockney do original para uma língua de chegada em que a marca de condição social é muito mais gramática do que fonética? Como, ainda assim, preservar a trama e os interesses de Higgins enquanto profissional da fonética? (Sobre o cockney, veja-se a NT 12).

Como evitar regionalismos na língua de chegada, que, no caso, seriam totalmente descabidos? Essa última questão implica: como produzir uma língua incorreta que seja, tanto quanto possivel, percebida como de âmbito neutro e nacional na maior parte do Brasil? Em outras palavras, tratar de produzir uma fala que se contraponha claramente à norma culta, mas que não venha a ser reconhecida por nenhum grupo de falantes como sendo típica de um outro grupo específico. E muito menos como típica de seu grupo.

Enfim, e mais que tudo, como manter a língua de chegada no mesmo plano central que a lingua-fonte ocupa no original?

As perguntas acima são específicas da situação sui generis de Pigmalião, e antecedem outras questões, essas já típicas da tradução teatral e da literária como um todo: traduzir ou não os nomes? Como tratar a diacronia histórica? Como recuperar situações e alusões específicas do tempo e do espaço do original, especialmente as que - como ocorre aqui - se refletem nas marcas da fala de uma personagem? Como produzir falas "faláveis"? Como...?

No que se segue nesta seção 1, indicaremos, em termos gerais, as respostas dadas a algumas dessas questões, buscando justificar, na medida do possível, as opções adotadas e valendo-nos, inclusive, um pouco do que se pode colher da teoria.

Algumas soluções específicas serão também tratadas aqui, a título ilustrativo. Entretanto, as soluções de tradução que julgamos de todo dignas de nota, e o respectivo racional, constam das Notas de Tradução (seção 2 abaixo) às quais o texto desta seção 1 remete. 


\subsection{Locação}

A própria história das opções adotadas ao longo dos anos quanto a se manter ou não a locação londrina nas traduções de Pigmalião é um indicativo do dilema colocado ao tradutor, ao menos nas primeiras traduções. Há uma tradução brasileira de Miroel Silveira, e que estreou em 1942, na qual a ação se passa no Rio de Janeiro, e não em Londres. Informa-nos o tradutor que ela foi, por isso, recebida com estranheza por "alguns criticos". Mas isso, diz, "só pode originar-se de um mesquinho conhecimento do inglês" já que "a peça deve ser uma aula de fonética que demonstre [...] os milagres de que é capaz [...] o adequado ensinamento da linguagem falada. Ora mantendo a ação da peça em Londres, não me seria possivel demonstrar, em português, esse fato essencial".

Mesmo que não se enxergue a lógica que justifica a última afirmação acima, é preciso reconhecer que Miroel Silveira poderia julgar que estava em boa companhia, já que, segundo afirma, seguiu nisso o exemplo "da maioria" - ao menos, a crer nesse tradutor, na maioria até então - "dos tradutores para outras linguas", inclusive a francesa, "autorizada por Shaw".

Entretanto, mais adiante Silveira se trai: "Se a peça perdeu com isso, a culpa não é minha”, o que soa como uma rendição - quase sem luta - de um tradutor ao intraduzivel. Por outro lado, não seria de estranhar que até mesmo Shaw se tivesse rendido ao chauvinismo lingüístico francês de então.

A outra tradução para o português a que tivemos acesso é de Portugal (trad. F. de Mello Moser, Editorial Verbo, 1972, vide a Nota ao final desta Introdução), e nela a ação se passa em Londres. O tradutor esclarece que "as particularidades dialectais do cockney não possuem correspondência sistemática na nossa língua", o que o levou a "recorrer a uma modalidade coloquial da língua portuguesa, que, à semelhança do original, exprimisse distância social, mais do que regionalismo".

Embora nossa decisão de manter a ação em Londres tenha sido tomada antes de que tivéssemos conhecimento dessa nota do tradutor português, devemos fazer nossas as palavras de Mello Moser. O surgimento da televisão no período que nos 
separa - e a Mello Moser - de Silveira, certamente tornou corriqueiro o que para Silveira era impensável: ingleses tendo aulas de fonética portuguesa em Londres. E nos faz ver o tamanho do abismo cultural que a chegada da mídia eletrônica cavou, entre o antes e o depois de seu advento.

Mas não só isso justifica a decisão tomada, o sentimento de que - não obstante Silveira - a ação necessariamente teria que ser mantida em Londres. Maria Sílvia Betti (2003: 122) ressalta que "o texto de onde se parte só é 'legivel' de forma plena dentro do contexto cultural de sua enunciação: tentar emular as características desse contexto e as relações nele produzidas por uma determinada peça é um equívoco tanto no que se refere ao trabalho da tradução como no da encenação". E cita Roberto Schwarz acerca "dos elementos de atualização cultural e de importação de idéias sem uma relação real com a vida da sociedade à sua volta".

Estamos portanto, nós também, em boa - e mais atual companhia em nossa decisão de manter em Londres a ação da peça. Nessa medida, é claro, mantém-se na tradução o sistema monetário inglês, não decimal, de então (vide NTs 3 a 6).

\subsection{O cockney}

Mas o grande desafio quando se trata de traduzir Pigmalião é o cockney (vide NT 12). Como já se disse acima, é de esperar que a marca, francamente fonética no inglês, passe no português a ter um peso gramatical mais considerável, até porque como também já se disse - é preciso evitar regionalismos.

Buscamos, to the best of our ability, alcançar o objetivo tal como já foi posto: produzir uma língua incorreta que seja, tanto quanto possível, percebida como de âmbito neutro e nacional na maior parte do Brasil.

Assim o "Say a cup of tea", da cena de lição de fonética no segundo ato (vide NT 10), tornou-se "Repita: 'O cão que eu trouxe tem um problema: pulgas"”, numa das poucas alterações de conteúdo que introduzimos. Liza repete: "U cão quieu trussi tem um pobrema: purga". "O problema são as pulgas”, corrige Higgins, 
e Liza mostra que afinal tem talento para a coisa, pronunciando "problema" corretamente de primeira.

Da mesma forma, as frases de Doolittle a Higgins que citamos acima, ortográfica e gramaticalmente corretas, transformamse em: "Craro qui são dotô. Si num fôssi eu pidia cinqüenta" e "Num posso mi dá essi luxu. I nem u dotô tinha si fôssi pobri quiném eu".

E a NT 11 discute uma fala de Higgins em que, além da obediência à diretriz de produção da língua incorreta, foi necessária uma sutil modificação de conteúdo, para que uma (muito mais sutil) alusão fosse preservada.

Ademais, apresentamos a seguir uma fala um pouco mais extensa de Doolittle na terceira cena do segundo ato (a cena que se segue à do banho de Eliza), de forma a propiciar ao leitor uma melhor idéia da solução que adotamos para o cockney, uma linguagem "incorreta" que é estigma social:

DOOLITTLE - Num diga íssu, dotô. Num fáli dessi jeitu. Qui quieu sô, meus dois dotô? Mi diguem, qui quieu sô? Sô um dus pobri ferradu qui num mereci nada nessa vida: é íssu quieu sô. Pensi nu qui é íssu prum homi. Qué dizê qui eli tá ferradu co'essas coisa di morá d'ocêis, di crásse, di média pra cima, u tempu todu. Si pinta uma coisa boa, i eu queru um pocu dela tamém, é sempri a mema história: "Cê num mereci, num é procê". Mas eu sô tão percisadu qui nem qui a mais di respeitu das viúva, qui recebi dinheru de seis caridadi diferenti, na mema semana, pru causu da morti du memu maridu. Eu num percisu menu du qui um homi di respeitu: percisu mais. Eu num comu com menas vontadi du qui eli i eu bebu muito mais. Eu queru um pocu di farra, eu sô um homi qui pensa. Eu queru alegria, i cantoria e uma banda quanu tô prá baxu. Eu tenhu di pagá iguár quiu di respeitu paga. Quiquié a morár dus di respeitu? Só uma disculpa pra nunca mi dá nada. Pur issu, eu peçu pus sinhô, comu dois dotô, di num vim cum essa prá cima di eu. Eu tô joganu limpu. Num façu di conta qui sô di respeitu. Eu num sô di respeitu; i tô a fim di continuá num senu. Eu gostu assim, íssu qui é verdadi. Os dotô vão tirá vantagi di um homi i pichinchá nu preçu da própria fía dêli, quieli criô i deu di cumê e vestiu cu suó du rostu até ela ficá interessanti prus dotô? Cincu libra num tá bom? Eu falei; agora mi digam. 
HIGGINS [levanta-se e aproxima-se de Pickering] Pickering, se ficássemos com esse homem por três meses, ele poderia escolher entre ser ministro de Governo ou um político popular no país de Gales.

É interessante notar o quanto Pigmalião desperta no tradutor a aguda consciência de estar "transferring not only the linguistic but a series of other codes as well' (Bassnett, 1985:89). Ao ter que alterar a própria língua para retratar estigma social, o tradutor tem que se colocar - literalmente avant la lettre - no lugar do ator, e se vê às voltas com muito mais do que "o essencial [que] decorre da transposição rítmica e prosódica que viabiliza a interpretação cênica" (Betti, 2003: 122). Vê-se o tradutor às voltas com muito mais do que é o requisito usual da tradução teatral, "o texto bien en bouche, ou seja, confortável de dizer e dotado de naturalidade ou plausibilidade" (idem, p. 123).

À parte o trabalho que dão para que se as produza de forma coerente e uniforme, o ponto a ressaltar-se é o quanto essas falas têm de intrinsecamente teatral, ou até mais do que isso, "metateatral". Sua própria leitura incomoda, os erros de ortografia forjam palavras que não se pode reconhecer de relance como numa leitura normal.

Assim, essas falas ficam entre "the verbal and the visual", são como que "illustrations [...] we must pay attention to" (Oittinen, 1996). (Vide NT 8, para uma outra situação em que, aí, uma ilustração propriamente dita, orientou a tradução). Obrigam, essas falas, o leitor - como obrigaram antes o tradutor ao produzi-las - a pronunciá-las ao menos mentalmente, dando uma atenção antecipada à "dicção, que impera na construção de sentido para o ouvinte e o espectador" (Betti, 2003: 123).

Compõem dessa forma um nivel anterior - já "performático", mesmo que ainda em written script - que antecede as próprias "five categories of expression in the making of a performan$c e$ ", de Tadeusz Kowzan:"[t]he performance text involves a range of sign systems, that harmonize with the written, extending that written text into space" (citado em Bassnett, 1996:88, 94). No caso em pauta, ao contrário, é o texto escrito que, em sua transgressão fonética, gramatical e ortográfica, "invade" esse espaço da performance e de certa forma a sobredetermina. 
E assim, é nesse "nivel anterior", na construção bem-sucedida ou não dessas falas, que o tradutor dessa peça suigeneris atingirá ou não o objetivo primordial mencionado mais acima: o de manter a língua de chegada, enquanto "personagem", no mesmo plano central que a lingua fonte ocupa na trama em inglês.

\subsection{Nomes de personagens}

Traduzir ou não os nomes de personagens seria questão superada, uma vez que se decidiu manter em Londres a ação do texto traduzido. De fato, os nomes, à exceção de dois, foram mantidos idênticos aos do texto original.

No entanto, quando um tradutor teatral do porte de Millôr Fernandes é citado (Betti: 131) afirmando acerca de nomes que "hoje sou a favor de traduzir tudo", e o faz inclusive em traduções de Shakespeare, cabe talvez algum comentário. Antes de mais nada, o "tudo", no caso, são os nomes de animais no Rei Lear. E é em As alegres matronas de Windsor, lembra-nos Betti, que Millôr traduz - deliciosamente - nomes próprios de personagens para Magrela, Passarinho, Nunca e Reduzido.

Nesse contexto, ao manterem-se os nomes não traduzidos em Pigmalião, tudo o que se perdeu foi a oportunidade de uma boa tradução para o "Doolittle" do sobrenome de Eliza e de seu pai. Julgamos que a esta altura, após noventa anos de permanente notoriedade, Doolittle tem seu nome tão ligado a Pigmalião (e My Fair Lady) que é impossivel traduzi-lo.

Em um dos nomes que traduzimos na peça há duplo sentido. Trata-se de Ezra D. Wannafeller, o benfeitor de Doolittle e benemérito de várias Sociedades de Reforma Moral mundo afora. Nesse caso, julgamos que caberia uma "tradução". A solução foi Ezra C. Vain-Prakee. Assim o "do you want a fellow?" com que Ezra se oferece em inglês a tantas Sociedades, torna-se em português o "cê vem pra qui?" com que tantas Sociedades (de Reforma Moral, é claro) tentam, sempre com sucesso, aliciar Ezra.

Quanto ao segundo nome traduzido, trata-se de Largelady Park, um local geográfico, onde a Sra. Eynsford Hill foi criada. A 
solução adotada foi Fartadonna Park. No caso, ao que tudo indica, Largelady Park é o nome inventado de um lugar inexistente e a alusão, julgamos, deveria ser preservada.

Ainda no que respeita a nomes, note-se que mesmo a aristocracia no nome dos Eynsford Hill não se perde em português. Lá e cá sobrenomes que, embora duplos, são "indivisíveis", são sinal de nobreza (decadente ou não), e assim o que há de pomposo no sobrenome de Freddy e Clara passa, mesmo em inglês, para o espectador brasileiro.

\subsection{A tradução de marcas de fala}

A última questão que apontamos no início foi a do tratamento a ser dado a uma alusão específica do tempo e do espaço do original, e que se reflete numa marca de fala de uma personagem. No caso, Higgins e sua recorrente interjeição "By George?".

Segundo o New Shorter Oxford Dictionary, George, além de nome próprio, designa uma jóia específica na insígnia da Ordem da Jarreteira, justamente a jóia que porta a efígie de São Jorge, patrono dessa que é a mais antiga ordem de cavaleiros da Europa (meados do sec. XIV). Ademais, George como uma interjeição de surpresa ou assertividade (que obviamente se originou na invocação do santo), toma na maioria das vezes a forma da frase interjectiva "By George!" e é registrada a partir do final do século XVI. Há, portanto, aristocracia suficiente na interjeição que marca a fala de Higgins.

Mas com certeza há mais. À época da estréia de Pigmalião (1913), o soberano inglês era também um George, o quinto desse nome, que ascendera recentemente ao trono (1910), depois de quase um século sem Georges. Assim, o socialista Shaw, ao decidir-se por essa marca em Higgins, obteve um efeito - entre o humor, a ironia e a crítica direta - que era certamente percebido por seu público. Higgins, o elitista esnobe, não exprime em "By George!" simplesmente espanto ou asserção, mas invoca a toda hora - de forma ambigua e supostamente inconsciente - o rei, então recém-coroado, de um império que já se sabia em vias de extinção. 
Mas pode-se recuperar isso para o espectador brasileiro em 2003? "Não há expressões intraduzíveis" - anima-nos Millôr numa nota que Betti reproduz (p. 138). Nela, Millôr descreve o caminho percorrido para solucionar com elegância um "trocadilho imbecil" de Sly na Megera domada. E, acrescenta, "[não há expressões intraduziveis] sobretudo em criações dramáticas e poéticas, que permitem uma ampla variação de escolhas".

Insurge-se assim Millôr contra a freqüência com que se recorre à "N.T.: Expressão intraduzivel", seja por distância na língua (como no trocadilho), seja por distância no tempo e no espaço (como no caso em pauta). E Betti (p. 132) nota: "a preocupação em reter o sabor e a graça de certas passagens leva Millôr a tomar liberdades com as estruturas sempre que isso resulta em aumento da eficácia expressiva" (grifo nosso). E também sempre que isso resultar em recuperação na língua de chegada de um efeito conseguido na língua-fonte, acrescentaríamos nós.

Assim, respaldados por Betti e Millôr, ousamos um pouco na busca da solução de "By George!". Há no português do Brasil de 2003 uma interjeição de origem francesa - ulalá! - que, se não está perdida no tempo, também não está freqüentemente nos lábios de ninguém, nem é marca da fala de ninguém na vida real (ou nas representações da vida real). Carrega, por outro lado, o ranço de "francês" (o que no caso é mau), de "bon-vivant" (o que é de neutro para bom), e de "positivo, mas - assim como a fonética de Higgins - nada que vá resolver o problema da humanidade" (o que, no caso, é bom).

E há também no Brasil o governante recém-chegado, e uma expressão - "Lula lá !"- que fora recentemente palavra de ordem de militância politica, e que hoje, embora em desuso, expressa a realidade do objetivo alcançado. E, se não há império a ser perdido, haverá em muitos um pouco de esperança perdida, e o desencanto com a realidade, que sempre deixa a desejar. Seja como for, é certo que há já hoje uma certa ironia em "Lula lá".

Optamos então por "tomar alguma liberdade com a estrutura" e forjar uma interjeição - lu-la-lá! - que fosse a tradução do By George!, na esperança de que cause no espectador brasileiro do início deste século algo análogo ao que sentiu o espectador britânico há quase um século. 
O "lu-la-lá!" tem, hoje, uma ambigüidade que é similar à acima apontada para o "By George!" em 1913. Por um lado, evoca a interjeição ("ulalá!"), que, aliás, poderia - no que concerne ao espectador brasileiro - até constar do texto original. Por outro lado, evoca também "Lula lá!", o governante que o "By George?" evocara no espectador inglês.

Desde logo reconhecemos, é claro, que a solução deixa muito a desejar, se comparada à elegância e à criatividade das soluções de Millôr. Fica de qualquer forma a tentativa, e talvez mais importante, o registro do processo de análise, pesquisa e busca de solução.

\subsection{Conclusão}

A solução discutida acima, e sobretudo as soluções dadas para as várias falas em cockney, clamam por um diretor e principalmente por atores que as corroborem. Diretor e atores que pelo menos por enquanto, e dada a própria natureza deste trabalho - nos faltam.

Encerramos assim esta introdução, e o próprio trabalho de tradução, com a sensação do inacabado, do still in progress. E, nesse sentido, mais uma vez Pigmalião se revela uma peça meta- (ou seria hiper-?) teatral, ao menos no que respeita à tarefa do tradutor. A estratégia cooperativa entre o tradutor, o diretor da peça e os atores, que Bassnett (1985: 91) recomenda como a mais conveniente para a tradução teatral é - neste caso gritantemente - a única aplicável.

O texto que chegará ao palco nunca será o que sai da pena do tradutor. Por mais conveniente e justificada que possa lhe parecer a tradução de uma marca de fala, ou a solução encontrada para a tradução do cockney, a língua é em Pigmalião a grande personagem e compõe em grande parte cada personagem.

Dá-se assim o "refluxo" da "invasão" do espaço de performance pelo written text, invasão que apontávamos na discussão da tradução das falas cockney. E nesse segundo momento são o diretor e os atores que invadem o espaço da tradução, "retraduzindo" a tradução, dando forma final ao texto que levarão ao palco. 
Enquanto esse segundo momento não chega, ficamos nós - como comentado acima, ao discutirmos a produção da tradução do cockney - na tripla condição de tradutores, ilustradores e atores.

Luigi Pirandello "argued that illustrators of books, actors and translators share a common difficulty inherent in their work. All three, in his view, falsify the original text [...]" (Bassnett: 93). Eis-nos então tradittori de Shaw por uma via tripla, que só Pigmalião poderia proporcionar.

Mas isso, só até que surja alguém disposto a encenar a peça (if ever) e conosco dividir o ônus da traição.

Até lá ficamos, para parodiar Pirandello, "seis tradutores à procura de uma troupe".

NOTA: À época em que, em 2003, realizamos o trabalho de tradução em pauta e redigimos a presente introdução, desconhecíamos a existência da tradução de Pigmalião por Millôr Fernandes (São Paulo, L\&PM, 1995, $2^{a}$ ed., 2005) que só veio ter às nossas mãos por ocasião da publicação de uma segunda edição em 2005. Anima-nos constatar que nessa tradução Millôr apontou dificuldades e adotou diretrizes bem próximas do que aqui se disse. Por exemplo, a recomendação de um português incorreto que busque ao máximo evitar o regionalismo, que Millôr produz, mas que - como nós - deixa à decisão final dos atores e diretor (vide pág. 17 e notas de rodapé à pág. 22 da segunda edição da tradução de Millôr). E, ao contrário do que, como visto acima, recomendara e fizera na tradução do Rei Lear, Millôr, como nós, não traduz os nomes dos personagens de Pigmalião. Também para Millôr, como para nós, Pigmalião é "um romance em cinco atos". Por outro lado, Millôr não viu a necessidade que vimos de encontrar uma tradução específica para o "By George!" de Higgins (vide p. ex. págs. 72 e 90 da tradução de Millôr). E para Millôr, Pigmalião é Pigmaleão.

\section{As Notas de Tradução}

Apresentamos a seguir as Notas de Tradução que incluímos em nosso trabalho. Informamos, para cada caso, a página 
do texto original na edição da Penguin de 1942, indicando também o contexto e/ou a parte da peça em que o trecho ocorre.

NT 1 No original: Pygmalion a romance in five acts (página 1 - título e subtítulo da peça)

Nossa tradução: Pigmalião um romance em cinco atos

Nota: A tradução do subtítulo de Pygmalion, "a romance in five acts", não é tão imediata como a princípio pode parecer e justificará alguma digressão. Mello Moser adota o "romance em cinco atos" com que ficamos. Miroel Silveira, tradutor e adaptador, "adapta" para "uma comédia em cinco atos", o que certamente não corresponde à intenção de Shaw, mas que, dada a leveza - da superficie - da peça, e do muito de ironia que contém, pode se justificar. Cria, porém, dificuldades no início da Seqüência, das quais também não fica totalmente livre a solução que adotamos.

Senão vejamos. "Romance" não é, a rigor, a tradução de "romance", ao menos na medida em que "um romance de Dostoievski" é a correta tradução de "a novel by Dostoievsky". O CONCISE dá como uma das acepções de "romance", "a literary genre with romantic love or highly imaginative unrealistic episodes forming the central theme", e foi essa acepção que grifamos a que Shaw pretendeu ao adotar o termo. Isso se depreende do início da Seqüência, na qual Shaw utiliza a acepção para, imediatamente, contradizê-la: "Now the history of Eliza Doolittle, though called a romance because the transfiguration it records seems exceedingly improbable, is common enough." E ai cita Nell Gwynne, que, já no séc. XVII, de vendedora de laranjas chegara a amante do rei da Inglaterra.

Miroel Silveira traduz o "though called a romance" por "qualificada embora como ficção", e aí recupera bastante o sentido, embora perca a referência ao subtítulo ao tê-lo traduzido por "comédia". Fica-se sem saber por que - e por quem - a história de Eliza foi qualificada como "ficção". Traduzir, entretanto, também o subtítulo como "uma ficção em cinco atos" perderia algumas acepções de "romance" importantes no caso específico de Pygmalion. Vejamos o Houaiss, para "romance": 
1. "Prosa, mais ou menos longa, na qual se narram fatos imaginários, às vezes inspirados em histórias reais, cujo centro de interesse pode estar no relato de aventuras, no estudo de costumes ou tipos psicológicos, na crítica social, etc."

2. "p. ext. relato marcado pelo exagero ou pela fantasia".

3. "fato real que, por ser muito exagerado, parece inacreditável".

$\mathrm{O}$ "mais ou menos longa" da acepção 1 acima corresponde a "novel", que, no CONCISE, está como "a ficticious prose story of book length". No entanto, em "romance" há também tudo o que grifamos. Por um lado, o "relato marcado pelo exagero" e o "parece inacreditável" pretendidos por Shaw ao empregar "roman$c e$ ". Por outro, e "além disso", a "prosa", a grande literatura de Shaw no Prefácio e na Seqüência, e que transborda pelas rubricas e pelas falas. E está também o "centro de interesse no estudo de costumes e na crítica social", ou seja, o vínculo com a realidade -"common enough"-de Pygmalion, e que Shaw trata de ressaltar no início da Seqüência. Por tudo isso, optamos por "um romance em cinco atos".

NT 2 No original: "...an e upside down indicates the indefinite vowel, sometimes called obscure or neutral, for which, though it is one of the commonest sounds in English speech, our wretched alphabet has no letter". (página xi - Prefácio)

Nossa tradução: “...um "e" ao contrário indica uma vogal indefinida, às vezes chamada de obscura ou neutra, para a qual, embora seja um dos sons mais comuns na lingua inglesa, o desprezivel alfabeto da mesma não possui nenhuma letra correspondente."

Nota: Embora este parágrafo - uma observação referente à representação fonética de um som do inglês - não caiba numa tradução para o português, decidimos mantê-lo para deixar registrada a revolta de Shaw contra a pobreza fonética do alfabeto romano, para representar à altura a riqueza fonética da língua inglesa.

NT 3 No original: "I can change half-a-crown" (página 19 $\mathrm{Na}$ saída do teatro, a florista tenta vender flores) 
Nossa tradução: "Possu trocá meia-coroa"

Nota: Moeda usada antigamente na Grã- Bretanha, que valia dois shillings e seis pence.

NT 4 No original: "Take this for tuppence." (página 19 Ver NT 5)

Nossa tradução: "Fiqui cum esses por dois pence."

Nota: Moeda inglesa correspondente a duas vezes um penny, ou seja, two pence.

NT 5 No original: "picking up a couple of florins..." (página 28 - Antes que deixe o teatro, Higgins joga algumas moedas no cesto da florista)

Nossa tradução: “...pegando um par de moedas de florim..."

Nota: Moeda britânica do século XIX equivalente a dois shillings.

NT 6 No original: "Picking up a half-soverign" (página 28 ver acima)

Nossa tradução: "pegando uma moeda de meio soberano"

Nota: Antiga moeda de ouro britânica, equivalente a 20 shillings.

NT 7 No original: "...routed from the hearthrug and drifting back to the piano..." (página 53 - Higgins e a sra. Pearce discutem sobre boas maneiras)

Nossa tradução: “...perdida a posição na lareira, sai batendo em retirada rumo ao piano..."

Nota: Procurou-se, nesta instrução de cena, recuperar algo da imagem "militar" de Shaw: [He comes to anchor in the hearthrug with the air of a man in an assailable position] e [routed from the hearthrug and drifting back to the piano]. Eis aqui a qualidade literária de algo que é muito mais do que uma mera instrução de cena (vide também NT 9).

NT 8 No original: "Alfred Doolittle is an elderly but vigorous dustman, clad in the costume of his profession..." (página 54 Doolittle chega à casa de Higgins para falar sobre a situação de Eliza com Higgins) 

ro..."

Nossa tradução: "Está vestido com seu uniforme de lixei-

Nota: Eis aqui uma situação em que a ilustração de Feliks Topolsky nos auxiliou na tradução. Estávamos entre "gari" e "lixeiro", e as definições dos dicionários não eram - ou não nos pareceram - suficientemente claras para permitir a distinção. A figura de Doolittle entrando em cena, que torna visível o chapéu descrito na correspondente rubrica, facilitou a decisão. The visual helped the verbal, Oitinnen gratia, e data venia Pirandello (vide nossa Introdução).

NT 9 No original: “...most musical, most melancholy” (página 56 - Doolittle e Higgins conversam)

Nossa tradução: "...todo música, todo melancolia"

Nota: Shaw cita aqui, John Milton em Il Penseroso: Sweet bird that shunn'st the noise of folly, / Most musical, most melancholy! / I woo to hear thy eeven-Song; que fora citado - de forma não muito elogiosa - por William Wordsworth e Samuel T. Coleridge em The Nightingale, das Lyrical Ballads de 1798: "And hark! the Nightingale begins its song, / 'Most musical, most melancholy' Bird! / A melancholy Bird? O idle thought! / In nature there is nothing melancholy." Em todo caso, esta era uma citação usual na época em que Shaw escreveu Pigmalião. Consta da décima edição, de 1919, das Familiar Citations, de John Bartlett (1820-1905). Note-se que, dada a situação em que a citação aparece em The Nightingale, é possivel que ela carregasse, ao tempo de Shaw, uma certa ironia, que certamente cai bem na rubrica que antecede a fala de Higgins. Tentamos emprestar, de alguma forma, essa ironia à tradução: "todo música, todo melancolia".

Deve-se notar ademais que o "pássaro", implicitamente mencionado na instrução de cena ("most musical...), reaparece logo a seguir na fala de Higgins acerca do "trinar selvagem" de Doolittle. E, é claro, o espectador que assiste à peça desconhece a instrução e perde a alusão. Mas não o leitor do livro Pygmalion. Fica nesse caso evidenciado o aspecto que apontamos na Introdução: as peças de Shaw transcendem o meramente teatral. E isso mesmo no corpo das peças, e não apenas nos extensos Prefácios. São obras maiores, feitas também para o leitor, e não tão-somente peças para o espectador. 
NT 10 No original: "Say your alphabet.” (página 65 - Higgins ensina pronúncia a Eliza)

Nossa tradução: "Diga: "O cão que eu trouxe tem um problema: pulgas."

Nota: No original, Higgins manda Eliza repetir o alfabeto. Como no Brasil a fonética de quem recita o alfabeto não é, como na Inglaterra, algo que sirva como indicativo da classe social, nossa Eliza comete erros gramaticais, principalmente de concordância verbal e nominal. Higgins, na nossa versão, pede que ela repita uma frase, onde os erros dela ficam patentes. Como visto na seção 1 acima, Eliza pronuncia inicialmente do seu jeito: "U cão qui eu trussi tem um pobrema: purga". Mas logo após um esforço específico em cima de "pobrema", consegue, surpreendentemente para Higgins, pronunciar "problema" corretamente.

NT 11 No original: "...it's a choice between the Skilly of the workhouse and the Char Bydis of the middle class; and I havnt the nerve for the workhouse." (página 121 - ver nota anterior)

Nossa tradução: “...é uma escolha entri u Asilu dus pobri i u Cabidi di imprêgo da crasse média, i eu num tenhu coragi prá encará o asilu."

Nota: A alusão é a "estar entre Cila e Caríbdes" ou "Scylla e Charibdes", na ortografia do tempo em que essa expressão era comum também em português. É uma alusão à mitologia grega, o estar-se frente à escolha entre um monstro marinho e um enorme redemoinho, na qual o evitar-se um aumenta o risco do outro. No original, Doolittle diz "between the Skilly of the workhouse and the Char Bydis of the middle class", literalmente "a sopa magra do asilo e o chá 'Compra-êssi' da classe média". (Para "skilly"="sopa magra" e "char"="chá", cf. o CONCISE, que esclarece se tratar "char" de um "coloquial britânico").

\section{NT 12 Nota sobre a tradução do cockney:}

Na pág. V do "Prefácio", Shaw nota que "it is impossible for an Englishman to open his mouth without making some other Englishman despise him". Essa observação, de cunho geral, reflete-se na trama da peça no emprego que Eliza e Doolittle, membros da classe desprovida, fazem do cockney, em contraste à $R P$, 
a "received pronounciation" da classe mais abastada à que Higgins pertence.

O termo "cockney" - literalmente, "ovo gorado, de galinha nova", ou seja, o ovo que não se desenvolveu a contento - era no século XVI pejorativamente usado pela população rural para designar os habitantes de grandes cidades em geral. É nesses termos que Robert Whittington (ca. 1520) refere-se aos "cockneys de [...] Londres, York ou Perugia", os quais, por serem urbanos, desconheciam o modo de vida do campo (Encycl. Brit., verbete “cockney"). A partir do século XIX e até hoje, o termo aplica-se de forma geral à população de Londres e, mais especificamente, aos habitantes de uma área bem restrita e pitorescamente delimitada: aquela coberta pelo som dos sinos da igreja de St. Maryle-Bow (id.).

Mas, claro, o cockney é também - e principalmente uma pronúncia "non-received" e de dificil compreensão para os da $R P$, diga-se. Assim, apenas em algumas falas Eliza (e os seus) pronunciam cockney. Por exemplo, ao início da peça, nas duas falas de Eliza que se seguem ao "tranco" com Freddy (p. 15 e 16 de Shaw, 1942, a edição que serviu de base para a tradução), e naquela em que Higgins reproduz Eliza pedindo a Pickering que lhe compre flores (id, p. 21, note-se que a fala de Eliza em si, à p. 18 , já fora pasteurizada por Shaw). Ou seja, pelo ininteligivel da pronúncia, Shaw acaba por reduzir, em parte, o "cockney" de Pygmalion a transgressões da, digamos, "received grammar".

Mas o fundamental é, como vimos, a "lingua como estigma". E, como no português do Brasil a "pronúncia inculta" é compreensivel ao "ouvido culto", pudemos (a rigor, tivemos) que juntar, com uma freqüência bem maior que a do próprio Shaw, transgressões de gramática e pronúncia/ortografia no "cockney caboclo" que tentamos produzir.

$\mathrm{E}$, assim, até mais freqüentemente que Shaw, vimo-nos entre "the verbal and the visual" (Oittinen, 1995), com tudo o que isso significa, como ressaltado na Introdução. E tudo graças a essa peça única que é Pygmalion e que consegue, nesse aspecto, oferecer mais aos tradutores do que ofereceu ao próprio autor. 


\section{Referências bibliográficas}

BASSNETT-MCGUIRE, Susan. (1985) "Ways through the Labyrinth: Strategies and Methods for Translating Theatre Texts". In: Theo Hermans, ed., The Manipulation of Literature: Studies in Literary Translation. London and Sydney: Croom Helm, p. 87-102.

BETTI, Maria Sílvia. (2003) “A tarefa do tradutor teatral”. In: Cadernos de Literatura Brasileira, número 15 - julho de 2003. São Paulo: Instituto Moreira Salles, p. 121-138.

"COCKNEY", verbete in Encyclopaedia Britannica, Walter Yust, ed., Encyclopaedia Britannica Inc., Chicago, Londres, Toronto, 1954, vol. 5, p. 916. (Encycl. Brit., verbete "cockney").

COLE, George D. H. (1954) "FABIAN SOCIETY", in Encyclopaedia Britannica, Walter Yust, ed., Chicago, London, Toronto: Encyclopaedia Britannica Inc., vol. 9, p. 20.

HENDERSON, Archibald (com um colaborador anônimo), "SHAW, GEORGE BERNARD”, in Encyclopaedia Britannica, Walter Yust, ed, Encyclopaedia Britannica Inc., Chicago, Londres, Toronto, 1954, vol. 20, p. 469A-470.

OITTINEN, Ritta. (1995) The Verbal and the Visual: On the Carnivalism and Dialogics of Translating for Children. In: Compar(a)ison: An International Journal of Comparative Literature, II/1995, Bettina Kümmerling-Meibauer, guest-editor. Bern: Peter Lang, p. 49-66.

RASULA, Jed \& MCCAFFERY, Steve. (1998) Imagining Language: An Anthology. Cambridge, Massachussets, London: MIT Press.

READ, Kingsley. (1998) Sound-writing 1892-1972: George Bernard Shaw and a modern alphabet. In: Journal of the Simplified Spelling Society, J23, 1998-1, p. 3-7.

SHAW, George Bernard. (1994) Pygmalion, unabridged. New York: Dover Publications, Inc.

. (1942) Pygmalion: a romance in five acts, ilustrações de Feliks Topolski. Toronto: Penguin Books.

. (1951) Pygmalion: a romance in five acts, Penguin Books, Baltimore.

- (1974) Pygmalion: a romance in five acts, ilustrações de Feliks Topolski. Toronto: Penguin Books.

. (1972) Pigmalião: romance em cinco actos, trad. F. de Mello Moser. Lisboa: Editorial Verbo.

TRADTERM, 12, 2006, p. 205-227 
- (1955) Pigmalião: comédia em cinco atos. Tradução e adaptação de Miroel Silveira. São Paulo: Editora Melhoramentos.

. (2005). Pigmaleão. Tradução de Millôr Fernandes. São Paulo: L\&PM.

THE NEW SHORTER OXFORD Dictionary of English, $3^{\text {a }}$ edição rev., 2 vols., Lesley Brown, ed., Clarendon Press, Oxford, 1993. (NSOD). THE CONCISE OXFORD Dictionary of Current English (1995) $9^{a}$ edição, Della Thompson, ed. Oxford: Clarendon Press. (CONCISE). 